\title{
AS MANIFESTAÇÕES DO PATRIARCADO NO LIBELO ACUSATÓRIO DO PROCESSO DE IMPEACHMENT DA EX-PRESIDENTE DILMA ROUSSEFF
}

\section{THE EXPRESSIONS OF THE PATRIARCHY IN THE LIST OF CHARGES OF THE EX-PRESIDENT DILMA ROUSSEFF'S IMPEACHMENT PROCESS}

\author{
Yara Ribeiro de Hollanda (URCA) ${ }^{1}$ \\ Edson Soares Martins (URCA) ${ }^{2}$ \\ Maria Elias Soares $(\mathrm{UFC})^{3}$
}

\section{RESUMO}

Segundo as lições de Saffioti $(1987 ; 2011)$ e Pateman (1993), o patriarcado é uma forma estruturante de nossa sociedade e se manifesta não apenas nas relações privadas, mas, também, nos espaços públicos. A exclusão de mulheres do espaço político é apenas uma das diferentes formas de manifestação desse patriarcado. O libelo acusatório como parte integrante do processo de impeachment da ex-presidente Dilma Rousseff e como um gênero discursivo produzido pela atividade jurídica, não está alheio às condições extraverbais de sua produção. Nesse estudo, utilizamos a perspectiva teórico-metodológica de análise dos gêneros discursivos desenvolvida por Bakhtin e o Círculo, além dos estudiosos contemporâneos de suas obras, para analisar o libelo acusatório do processo de impeachment percebendo as manifestações do patriarcado. Nossas conclusões são de que esse gênero discursivo integrante do processo de impeachment se valeu de uma forma jurídica estilisticamente aceita, da construção composicional e do conteúdo temático próprios da acusação processual, para legitimar o discurso patriarcal de exclusão da mulher dos espaços públicos e dos cargos de poder.

PALAVRAS-CHAVE: Patriarcado; Libelo Acusatório; Impeachment.

\begin{abstract}
According to the lessons of Saffioti $(1987 ; 2011)$ and Pateman (1993), patriarchy is a structuring form of our society and manifests itself not only in private relations, but also in public spaces. The exclusion of women from political space is just one of the different forms of manifestation of this patriarchy. The impeachment process of ex-president Dilma Rousseff, as a discursive genre produced by legal activity, is not unrelated to the extraverbal conditions of its production. In this study, we use the theoretical-methodological perspective of discursive genres analysis developed by Bakhtin and the Circle, as well as the contemporary scholars of their works, to analyze the list of charges of the impeachment process perceiving the manifestations of patriarchy. Our conclusions are that this discursive genre that is part of the impeachment process used a stylistically accepted legal form, the compositional construction and thematic content of the procedural accusation, to legitimize the patriarchal discourse of excluding women from public spaces and positions power.
\end{abstract}

KEYWORDS: Patriarchy; List of charges; Impeachment.

\footnotetext{
${ }^{1}$ Especialista em Direito Constitucional e Mestranda do Programa de Pós-Graduação em Letras da Universidade Regional do Cariri. E-mail: yara.hollanda@urca.br.

2 Doutor em Letras pela Universidade Federal da Paraíba.E-mail: edson.soares@urca.br.

${ }^{3}$ Doutora em Letras pela Pontifícia Universidade Católica do Rio de Janeiro. E-mail: melias@ufc.br.
} 


\section{INTRODUÇÃO}

Analisar o processo de impeachment da ex-presidente Dilma Rousseff é como ter diante de si um fluxo de mais de cem anos de história da República brasileira. A ex-presidente foi a primeira mulher eleita para exercer a chefia do Poder Executivo federal desde a proclamação da República, em 1889. As manifestações patriarcais que se observam no seu governo e no posterior processo de impeachment tiveram início já nas campanhas eleitorais que envolveram a figura do expresidente Luís Inácio Lula da Silva como principal apoiador de sua campanha. Em muitas ocorrências discursivas, percebeu-se a crença - e, mesmo, a defesa - de que, para que uma mulher tenha podido ser eleita presidente da República, foi necessário que uma figura masculina tivesse endossado sua candidatura e sua competência para exercer o cargo. Em um raciocínio aplicável ao caso, Bourdieu nos recorda que "a força da ordem masculina se evidencia no fato de que ela dispensa justificação: a visão androcêntrica impõe-se como neutra e não tem necessidade de se enunciar em discursos que visem a legitimá-la" (BOURDIEU, 2014, p. 22).

A relevância das análises que se seguem se deve ao fato de que, além do aspecto histórico e social já mencionado, a sanção sofrida por Dilma Rousseff é uma das mais complexas previstas pelo ordenamento jurídico brasileiro. Isto acontece porque envolve não apenas a Constituição Federal, como, também, a Lei 1.079/50 e, de forma subsidiária, os Regimentos Internos da Câmara dos Deputados e do Senado Federal. Além disso, o impeachment da ex-presidente Dilma foi um marco do fim do governo petista, iniciado em 2003, com o primeiro mandato de Lula como chefe do Poder Executivo federal.

Inicialmente, é importante esclarecermos a escolha que adotamos, no sentido de analisar as manifestações do patriarcado no processo de impeachment, tendo em vista que há discussões sobre a validade desse termo dentro da própria academia. Pateman (1993) nos dá uma ideia do contexto complexo que envolve o uso do termo:

[...] Houve várias discussões entre as feministas sobre o significado de "patriarcado" e sobre questões tais como: se em nossa sociedade o termo deve ser usado em seu sentido literal de governo paterno; se o patriarcado é uma característica humana universal ou se ele é histórica e culturalmente variável; se o matriarcado ou a igualdade sexual existiram alguma vez, e, caso tenham existido, como aconteceu a "derrota mundial e histórica do sexo feminino" (para utilizar a dramática formulação de Engels); se as relações patriarcais estão essencialmente estabelecidas na família ou se a vida social, como um todo, está estruturada pelo poder patriarcal; e quais as relações existentes entre patriarcado, ou dominação sexual, e capitalismo, ou dominação de classe. Não existe um consenso acerca de nenhuma dessas questões e as feministas utilizam o termo "patriarcado" em muitos sentidos. Algumas argumentam que os problemas com o conceito são tão grandes que ele deveria ser abandonado. (PATEMAN, 1993, p. 39, aspas no original).

Apesar dessas questões que envolvem o emprego do termo, concordamos com Saffioti (2011), quando ela afirma que "Colocar o nome da dominação masculina - patriarcado - na sombra significa operar segundo a ideologia patriarcal, que torna natural essa dominaçãoexploração" (SAFFIOTI, 2011, p. 56, itálico no original). Em sentido semelhante, tal direção

[...] representaria, na minha maneira de entender, a perda, pela teoria política feminista, do único conceito que se refere especificamente à sujeição da mulher, e que singulariza a forma de direito político que todos os homens exercem pelo fato de serem homens. Se o problema não for nomeado, o patriarcado poderá muito bem ser habilmente jogado na obscuridade, por debaixo das categorias convencionais da análise política. (PATEMAN, 1993, p. 39). 
As relações hierarquizadas estabelecidas pelo patriarcado, segundo Saffioti (2011), permeiam todos os espaços da sociedade. Sobre a escolha que nos conduz a analisarmos o patriarcado e não enveredarmos pela discussão das relações de gênero ou pela ideologia machista, concordamos com Pateman (1993), quando ela afirma que, mesmo dispondo de outros termos para se referir a essas relações hierarquizadas, não há razões para abandonar o uso do termo patriarcal. A estudiosa britânica afirma:

Grande parte da confusão surge porque "patriarcado" ainda está por ser desvencilhado das interpretações patriarcais de seu significado. Até as discussões feministas tendem a permanecer dentro das fronteiras dos debates patriarcais sobre o patriarcado. [...] Abandonar o conceito significaria a perda de uma história política que ainda está para ser mapeada. (PATEMAN, 1993, p. 39-40, aspas no original).

Portanto, analisar as manifestações do patriarcado significa adentrar em uma estrutura presente em diversos âmbitos da sociedade. Para isto, buscamos a obra de Bakhtin e do Círculo, que nos oferece suporte metodológico para analisarmos como o patriarcado está presente nos documentos do impeachment. Investigamos, desta maneira, o patriarcado manifestando-se no gênero discursivo, o que permite a descrição do conteúdo temático de que ele se serve, além de propiciar a demonstração de como a construção composicional o absorve e de como o estilo lhe dá aceitabilidade.

Como se trata de um processo, independentemente de sua natureza jurídica, o impeachment produz, em cada uma de suas fases, diversos gêneros discursivos. Daí a importância de trazermos Bakhtin e o Círculo para uma pesquisa ligada ao campo jurídico, pois seu arcabouço teórico pode entrar em contato com diversas áreas, inclusive as que não tratam especificamente das teorias linguísticas. Afinal, Bakhtin é "um pensador complexo, multifacetado e contraditório, cujo leque temático abrangia desde questões filosóficas primeiras até uma concepção da literatura bastante original" (FARACO; TEZZA; CASTRO, 2006, p. 13). Além disso, o Círculo "era constituído por pessoas de diversas formações, interesses intelectuais e atuações profissionais (um grupo multidisciplinar, portanto)" (FARACO, 2003, p. 15). Esses múltiplos olhares sobre as questões relacionadas à linguagem e outros aspectos de natureza filosófica nos auxiliaram em uma melhor compreensão do gênero discursivo libelo acusatório.

A respeito do gênero discursivo escolhido, é importante esclarecermos que nossa ideia inicial era fazer uma análise das alegações finais dos denunciantes. Em uma consulta ao site do Senado, percebemos que um mesmo documento, o libelo acusatório, é apresentado duas vezes no site: uma quando se buscam as acusações e outra quando se buscam as alegações finais. Diante da dificuldade de se chegar, pelo site, até às alegações finais dos denunciantes, optamos por analisar o libelo acusatório. Tal opção carrega a vantagem de focalizar o documento acusatório inicial, pois é a partir dele que todos os demais gêneros processuais se desenvolvem.

O objetivo central do presente estudo é, portanto, analisar as manifestações do patriarcado que ocorrem no libelo acusatório do processo de impeachment da ex-presidente Dilma Rousseff sob a ótica bakhtiniana e do Círculo. Também nos valemos das contribuições dos estudiosos contemporâneos desses pensadores. Nossas discussões serão apresentadas em duas seções: na primeira, trazemos o conceito de gênero discursivo e fazemos a apresentação da arquitetônica do libelo acusatório consoante a perspectiva bakhtiniana. Na segunda seção que compõe esse trabalho, analisamos as manifestações do patriarcado no libelo acusatório apresentando, ao final, nossas considerações.

\section{0 libelo acusatório e os gêneros discursivos}

O processo de impeachment é definido por Bulos (2011, p. 1239) como "a prerrogativa institucional do Poder Legislativo que consiste numa sanção de índole político-administrativa, 
encarregada de destituir, de modo legítimo e constitucional, o Presidente da República”. Segundo o autor, em cada uma das fases do processo de impeachment, faz-se necessária a observância de uma série de atos e procedimentos. Cada um desses atos faz uso da linguagem através de tipos de enunciados relativamente estáveis, os chamados gêneros do discurso (BAKHTIN, 2016).

Entendamos, primeiramente, o que é o libelo acusatório. De forma simplificada, o libelo acusatório era uma peça processual comum no direito penal antes da reforma introduzida pela Lei 11.689/08. O libelo trazia uma exposição do fato criminoso atribuído ao acusado, as condições de agravamento de pena e era submetido à apreciação da defesa do réu. As informações contidas no libelo deveriam estar em conformidade com a sentença de pronúncia e estavam restritas ao que havia sido apurado na fase de instrução processual. Diante do libelo, o acusado já sabia as acusações às quais responderia e as circunstâncias agravantes ou qualificadoras do crime. Excluía-se, dessa forma, o fator surpresa da defesa do acusado. Com o advento da Lei 11.689/08, essa peça processual foi extinta, visando dar maior celeridade ao processo penal. Entretanto, as modificações trazidas pela Lei 11.689/08 não se aplicam ao processo de impeachment, tendo em vista que, apesar de julgar crimes de responsabilidade, ele não é regido pelos ritos dispostos no Código de Processo Penal e sim, pela Constituição Federal, pela Lei 1.079/50 e, de forma subsidiária, pelos Regimentos Internos da Câmara dos Deputados e do Senado Federal, como já dissemos. Observando, ainda, o libelo acusatório no processo de impeachment, percebemos, então, que se trata de um gênero discursivo na concepção bakhtiniana: o libelo é elaborado em um campo da atividade humana (a atividade jurisdicional); o emprego da língua se dá por meio de enunciados concretos que possuem conteúdo, estilo e construção composicional próprios e está ligado a uma finalidade típica desse campo da atividade.

Nesse trabalho, analisaremos, portanto, elementos que compõem o gênero discursivo libelo acusatório. Precisaremos fazer incursões pela obra de Bakhtin e do Círculo, para apresentar os conceitos que nos auxiliarão nessa empreitada, entre os quais tomamos, como ponto de partida, o conteúdo. Segundo Bakhtin (2016), o conteúdo semântico-objetal "é o primeiro elemento do enunciado que determina as suas peculiaridades estilístico-composicionais" (BAKHTIN, 2016, p. 47).

Dessa forma, o primeiro aspecto a ser observado no libelo acusatório diz respeito ao seu conteúdo semântico-objetal. O libelo acusatório possui uma finalidade específica dentro do campo jurídico: ele imputa uma conduta criminosa a alguém. No caso do impeachment, aponta os crimes de responsabilidade cometidos pelo(a) Presidente da República. A análise do conteúdo é importante, pois, segundo Bakhtin (2017), o conteúdo deve estar relacionado com o mundo do conhecimento e do ato ético, para que sua forma seja esteticamente significante. Sem nos adentrarmos muito na dimensão filosófica da questão, fixaremos nossa atenção no fato de que Bakhtin (2017) afirma que o ato ético é aquele considerado em sua integridade. Dessa forma, apesar de ser um elemento importante, não podemos analisar o libelo acusatório, como também nenhum outro gênero discursivo, considerando apenas seu conteúdo. Essa análise seria inviável em uma perspectiva bakhtiniana. Correríamos o risco de ignorar aspectos da construção composicional do enunciado que tornam sua forma esteticamente significante.

Seguindo pelo pensamento bakhtiniano, o segundo elemento a determinar a composição e o estilo de um enunciado é o elemento expressivo. O elemento expressivo é "a relação subjetiva emocionalmente valorativa do falante com o conteúdo do objeto e do sentido do seu enunciado" (BAKHTIN, 2016, p. 47). O elemento valorativo é, segundo Faraco (2009, p. 97), o "constituinte nuclear de todo pensamento de Bakhtin sobre qualquer manifestação verbal". Segundo Bakhtin (2017, p. 87), "nenhum conteúdo seria realizado, nenhum conteúdo seria realmente pensado, se não se estabelecesse um vínculo essencial entre o conteúdo e o seu tom emotivo-volitivo". Percebemos que, para o autor, o sistema de valoração faz parte da arquitetônica ${ }^{4}$ do gênero

\footnotetext{
${ }^{4}$ O conceito está presente em várias obras de Bakhtin e do Círculo, designando, em termos gerais, o ato unitário singular e "os momentos concretos fundamentais da sua construção e da sua disposição recíproca. Estes
} 
discursivo. Volóchinov (2018) corrobora o pensamento bakhtiniano sobre a questão axiológica ao afirmar que, sem ênfase valorativa, não há palavra.

É importante abrir espaço para uma discussão que por muito tempo permeou a academia nos cursos jurídicos: a suposta neutralidade discursiva. Em alguns momentos, a neutralidade discursiva foi entendida como sinônimo de imparcialidade. Consoante os adeptos dessa concepção, deveria se utilizar um discurso neutro como forma de se garantir a imparcialidade da justiça. Como o próprio Bakhtin afirma, entretanto, “[...] um enunciado absolutamente neutro é impossível" (BAKHTIN, 2016, p. 47). Como o libelo acusatório é um gênero discursivo ligado a um campo da atividade humana, ele também está condicionado à relação valorativa que o enunciador tem em relação ao seu conteúdo semântico-objetal. Essa relação, segundo Bakhtin (2016), vai determinar a escolha dos recursos lexicais, gramaticais e composicionais do enunciado, além de ser um fator preponderante na determinação do estilo individual. A entonação expressiva não deixa de ser percebida no discurso escrito, ela está presente e é possível percebê-la "graças ao contexto que emoldura o discurso do outro" (BAKHTIN, 2016, p. 60). Portanto, não podemos considerar apenas o conteúdo semântico-objetal do libelo acusatório, temos que analisá-lo de modo que o associemos ao seu valor expressivo. O libelo acusatório, ao discorrer sobre as condutas imputadas à ex-presidente, apresenta, também, a avaliação que os enunciadores têm desses atos e a expectativa de uma recepção desta avaliação junto ao outro, que, no caso, seriam tanto o Ministro que preside o processo quanto Deputados e Senadores, membros do tribunal.

Ainda em relação ao estilo do enunciado, outro aspecto de grande relevância são suas tonalidades dialógicas. Isso porque, segundo Bakhtin, o enunciado

[...] é pleno de tonalidades dialógicas, e sem levá-las em conta é impossível entender até o fim o estilo do enunciado. Porque a nossa própria ideia [...] nasce e se forma no processo de interação e luta com os pensamentos dos outros, e isso não pode deixar de encontrar seu reflexo também nas formas de expressão verbalizada do nosso pensamento. (2016, p. 59, itálico no original).

Essas tonalidades dialógicas não devem, entretanto, ser entendidas em seu sentido estrito. Volóchinov afirma que:

[...] o diálogo pode ser compreendido de modo mais amplo não apenas como a comunicação direta em voz alta entre pessoas face a face, mas como qualquer comunicação discursiva, independentemente do tipo. [...] Desse modo, o discurso verbal impresso participa de uma espécie de discussão ideológica em grande escala: responde, refuta ou confirma algo, antecipa as respostas e críticas possíveis, busca apoio e assim por diante. (2018, p. 219).

Não é possível entender plenamente o enunciado sem compreender seu caráter dialógico, pois "O enunciado de um sujeito apresenta-se de maneira acabada permitindo/provocando, como resposta, o enunciado do outro" (MARCHEZAN, 2006, p. 117). O enunciado traz consigo enunciados de outros, pois ele é "um elo na cadeia da comunicação discursiva" (BAKHTIN, 2016, p. 60). Dessa forma, o enunciado está ligado, consequentemente, aos enunciados anteriores como, também, aos posteriores. O enunciado é construído levando-se em consideração uma compreensão responsiva ativa do destinatário. O libelo acusatório exibe essa característica dialógica, pois ele está ligado aos enunciados que o antecederam e aos que o precederam.

Como observamos anteriormente, outro aspecto constitutivo dos enunciados, segundo a teoria bakhtiniana, é o seu destinatário. Dessa forma, cada gênero do discurso "[...] em cada campo da comunicação discursiva tem a sua concepção típica de destinatário que o determina

momentos fundamentais são: eu-para-mim, o outro-para-mim e eu-para-o-outro; todos os valores da vida real e da cultura se dispõem ao redor destes pontos arquitetônicos fundamentais do mundo real do ato: valores científicos, estéticos, políticos (incluídos também os éticos e sociais) e, finalmente, religiosos” (BAKHTIN, 2017, p. 114-115). 
como gênero" (BAKHTIN, 2016, p. 63). O destinatário pode ser um interlocutor direto, pode ser uma coletividade, um público especializado, um povo; como pode ser um destinatário presumido ou, ainda, ser uma instância projetada, desencarnada (um sobredestinatário).

Como podemos observar na figura 1 , existe um destinatário explícito indicado no endereçamento da peça processual: o Ministro Ricardo Lewandowski. Levando-se em consideração, entretanto, toda a arquitetônica que envolve esse discurso, percebemos que existe um outro destinatário que não está explícito: a defesa da ex-presidente Dilma. Os enunciados produzidos no libelo acusatório não são dirigidos exclusivamente ao destinatário explícito, mas, também, dialogam com as possíveis atitudes responsivas que a defesa poderia expressar, conforme se observa na figura 2 .

Figura 1: Endereçamento do Libelo Acusatório.

EXCELENTÍSSIMO SENHOR PRESIDENTE DO JULGAMENTO DA
DENÚNCIA 01/2016, EM CURSO PERANTE O SENADO FEDERAL,
DIGNÍSSIMO MINISTRO RICARDO LEWANDOWSKI.

Fonte: $<$ https://www12.senado.leg.br/noticias/materias/2016/08/22/veja-os-principais-documentos-do-processode-impeachment-de-dilma-rousseff>. Acesso em: 23 abr. 2021.

Figura 2: Trecho do Libelo Acusatório.

Resgatar tal aspecto se revela essencial, pois, contrariamente ao

presumido pela defesa, o parecer exarado pelo Procurador da República Ivan Marx, no

âmbito penal, não exculpa a denunciada.

Fonte: <https://www12.senado.leg.br/noticias/materias/2016/08/22/veja-os-principais-documentos-do-processode-impeachment-de-dilma-rousseff $>$. Acesso em: 23 abr. 2021.

$\mathrm{Na}$ figura 2, temos que os denunciantes presumem um possível argumento que poderia ser utilizado pela defesa da ex-presidente: o relatório do Procurador da República. Nesse relatório, o Procurador afirmara que não havia crimes penais relacionados às condutas da ex-presidente Dilma. Os denunciantes vislumbraram, portanto, que esse poderia ser um argumento levantado pela defesa para arguir a inocência de Dilma, diante dos crimes de responsabilidade a ela imputados, e buscaram refutá-lo de imediato. As figuras 1 e 2 corroboram a afirmativa bakhtiniana de que "o direcionamento, o endereçamento do enunciado, é sua peculiaridade constitutiva sem a qual não há nem pode haver enunciado" (BAKHTIN, 2016, p. 68).

Além do destinatário, o estilo "é indissociável de determinadas unidades temáticas" (BAKHTIN, 2016, p. 18). Para tratar da questão do tema e da significação, Volóchinov afirma que:

O tema do enunciado é definido não apenas pelas formas linguísticas que o constituem - palavras, formas morfológicas e sintáticas, sons, entonação -, mas também pelos aspectos extraverbais da situação. Sem esses aspectos situacionais, o enunciado torna-se incompreensível, assim como aconteceria se ele estivesse desprovido de suas palavras mais importantes. [...] O enunciado só possui um tema ao ser considerado um fenômeno histórico em toda a sua plenitude concreta. (2018, p. 228, itálico no original) 
O tema do libelo acusatório não é apenas seu assunto, suas formas linguísticas, seus recursos lexicais ou a significação das palavras que o compõem. O tema do libelo acusatório refere-se a suas nuances sociais, políticas e históricas, ou seja, refere-se a todos os aspectos de sua arquitetônica. Lembramos, entretanto, que não é possível, segundo Volóchinov (2018), traçar um limite absoluto entre tema e significação. Novamente, a compreensão do ato ético, ou seja, do ato em sua totalidade, mostra-se essencial em qualquer abordagem que tenha como objeto de estudo o enunciado concreto.

Até agora, vimos vários elementos relacionados ao estilo e como eles o determinam. A concepção de estilo, segundo Brait (2005), pode ir além da busca por traços individuais de expressividade. A função acusatória e a necessidade de formalização do discurso jurídico, através de enunciados escritos, além da questão procedimental prevista na legislação, fazem com que o libelo acusatório se apresente como o gênero discursivo mais adequado, do ponto de vista estilístico, para apresentar uma acusação contra o(a) Presidente da República em um processo de impeachment.

Feitas essas considerações iniciais, daremos continuidade apresentando as análises que foram feitas do libelo acusatório.

\section{Analisando o libelo acusatório}

Ao nos propormos a desenvolver uma análise sobre os documentos do processo de impeachment da ex-presidente Dilma Rousseff, precisamos levar em consideração que essa análise já se inicia com a própria disposição dos documentos no site do Senado ${ }^{5}$. Como dito anteriormente, o libelo é apresentado duas vezes no site, uma das ocorrências é quando se busca pelas alegações finais.

Ao apresentar o libelo acusatório como alegações finais dos denunciantes, produz-se um efeito de apagamento desta peça processual. Em uma análise dialógica dos enunciados, precisamos levar em consideração não apenas a materialidade discursiva, mas a situação em que o enunciado emerge, pois o dialogismo

[...] se impõe nos domínios do texto porque seu sentido só pode se produzir como efeito de encontro com outros textos. A explicação e o reconhecimento de uma significação no interior de um sistema ou de uma estrutura, implicam uma única relação, um único sujeito, enquanto que a interpretação e a construção do sentido implicam uma relação entre dois sujeitos falantes. (AMORIM, 2004, p. 190).

Prosseguindo com a análise do site, encontramos o libelo acusatório disposto novamente para consulta, mas com a nomenclatura correta. Surge, então, a questão: onde estão disponibilizadas as alegações finais dos denunciantes? Para termos acesso ao processo de impeachment, na íntegra, é preciso possuir certa expertise no conhecimento das ferramentas do site do Senado. É necessário saber o número da denúncia apresentada contra a ex-presidente Dilma Rousseff (número 1/2016); além disso, percorrer, através do comando de buscas, cerca de cem ocorrências para o termo alegaçôes finais, até que se chegue ao documento correto. Sem utilizar as ferramentas de busca, o usuário depara-se com setenta volumes de documentos, no formato PDF, para consulta, até que se chegue às alegações finais dos denunciantes. Como pudemos observar, a própria disposição das informações no site do Senado não facilita o acesso a pessoas com pouco domínio das ferramentas de informática ou com pouco conhecimento jurídico.

Feitas essas considerações sobre a disponibilização dos documentos do impeachment para consultas públicas, entendendo que elas fazem parte da situacionalidade denunciativa, como preconizam os estudos do Círculo bakhtiniano, passaremos às análises das manifestações do

\footnotetext{
${ }_{5}^{5}$ Disponível em: https://www12.senado.leg.br/noticias/materias/2016/08/22/veja-os-principais-documentos-doprocesso-de-impeachment-de-dilma-rousseff. Acesso em: 23 abr. 2021.
} 
patriarcado no libelo acusatório. Uma primeira manifestação do patriarcado, nesse gênero discursivo, se dá na parte inicial referente à qualificação das partes:

Figura 3: Apresentação dos peticionantes.

HELIO PEREIRA BICUDO, MIGUEL REALE JÚNIOR e
JANAINA CONCEIÇÃo PASCHOAL, denunciantes nos presentes autos, em
consonância com o disposto no artigo 24 da Lei $1.079 / 50$ e com o rito estabelecido pelo
Supremo Tribunal Federal, vêm, respeitosamente, perante Vossa Excelência, apresentar
LIBELO ACUSATÓRIO, nos seguintes termos:

Fonte: <https://www12.senado.leg.br/noticias/materias/2016/08/22/veja-os-principais-documentos-do-processode-impeachment-de-dilma-rousseff>. Acesso em: 23 abr. 2021.

$\mathrm{Na}$ figura 3, percebemos que são três os denunciantes, dois deles são homens e uma é mulher. A disposição dos nomes dos denunciantes, como observamos, segue um parâmetro patriarcal: do homem mais velho para o homem mais novo e, por último, vem o nome da mulher. Manifesta-se aí a relação patriarcal, entre os denunciantes, no respeito pela posição hierárquica do homem mais velho. Esse fato poderá, também, ser constatado na figura 4, em que as assinaturas dos dois advogados homens encontram-se dispostas na mesma linha e, novamente, seguindo a disposição hierárquica do homem mais velho para o homem mais novo; enquanto a assinatura da advogada encontra-se localizada em linha abaixo das assinaturas dos advogados, centralizada e isolada das demais:

Figura 4: Assinaturas 6 .

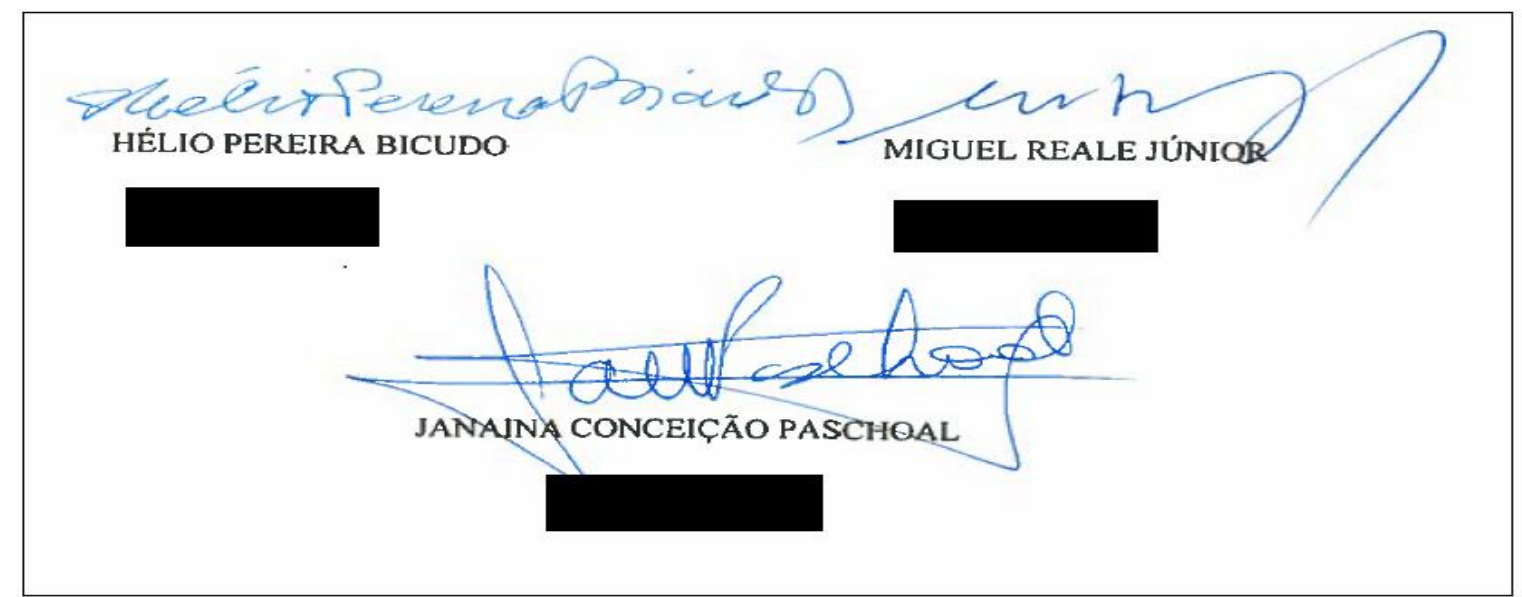

Fonte: <https://www12.senado.leg.br/noticias/materias/2016/08/22/veja-os-principais-documentos-do-processode-impeachment-de-dilma-rousseff $>$. Acesso em: 23 abr. 2021.

Conforme a teoria da multimodalidade de Kress e Van Leeuwen (1996), existe uma hierarquia do que está disposto no centro do texto visual em relação ao que se encontra na periferia da imagem. A figura 5 confirma essa hierarquia:

\footnotetext{
${ }^{6}$ No documento original, aparecem os números de inscrição na OAB de cada um dos advogados. Apesar de se tratar de um documento de acesso público, optamos por apagar esses dados por serem informações pessoais que não interferem nas análises que se seguem.
} 
Figura 5: Trecho do Libelo Acusatório

Além da regular notificação das testemunhas acima, solicita-se que

Vossa Excelência autorize a transmissão de um depoimento do primeiro denunciante, Hélio

Bicudo, em Plenário, seja na fase da oitiva das testemunhas de acusação, seja no momento das

sustentações orais.

\section{Em razão de problemas de saúde, Hélio Bicudo, que já completou 94}

anos, não pode viajar para Brasília. No entanto, gostaria muito de, oficialmente, falar aos

Senhores Senadores, ainda que em depoimento gravado.

Fonte: <https://www12.senado.leg.br/noticias/materias/2016/08/22/veja-os-principais-documentos-do-processode-impeachment-de-dilma-rousseff $>$. Acesso em: 23 abr. 2021.

No primeiro parágrafo, encontramos a expressão primeiro denunciante para fazer menção ao advogado Hélio Bicudo, ou seja, os demais denunciantes reconhecem que este deva ocupar a posição inicial como denunciante, dada a sua idade. O respeito pela posição hierárquica do homem mais velho é observado, portanto, tanto na disposição dos nomes na parte de qualificação, quanto na disposição das assinaturas. Importante, nesse momento, trazermos algumas notas biográficas envolvendo os peticionantes. Hélio Pereira Bicudo ${ }^{7}$ foi promotor em diversas cidades paulistas, procurador-geral do Estado de São Paulo, ingressou na carreira política pelo Partido dos Trabalhadores, sendo eleito deputado pelo Estado de São Paulo em 1990. Participou das votações a favor do impeachment do ex-presidente Fernando Collor de Mello em 1992. Em setembro de 2006, Bicudo afastou-se do PT em meio às denúncias de corrupção em que o partido se envolvera. Em setembro de 2015, protocolou, junto à Câmara dos Deputados, um dos pedidos de impeachment conta a ex-presidente Dilma. Miguel Reale Júnior ${ }^{8}$ foi professor da Faculdade de Direito da Universidade de São Paulo, membro do Conselho Federal da Ordem dos Advogados do Brasil e foi um dos redatores do pedido de impeachment do ex-presidente Collor. Durante o período de 2005 e 2006, foi a favor do processo de impeachment do expresidente Luís Inácio Lula da Silva. Janaína Conceição Paschoal ${ }^{9}$ é professora associada da Universidade de São Paulo, ligada ao departamento de Direito Penal, Medicina Forense e Criminologia. Elegeu-se deputada do Estado de São Paulo pelo Partido Social Liberal em 2018. Importa destacarmos que Paschoal foi orientada por Reale Júnior em sua tese de doutorado, defendida em 2002, na Universidade de São Paulo (USP). A relação de senioridade hierárquica, constitutiva da dominação patriarcal que aqui se discute, já se consubstanciava na relação orientador/orientanda precedente ao processo de impeachment da ex-presidente Dilma.

Outra manifestação evidente do patriarcado, no bojo do libelo acusatório, diz respeito aos doutrinadores citados para fundamentar as alegações dos denunciantes: não há, dentre eles, nenhuma mulher. Reflete-se aí uma condição patriarcal dos próprios cursos jurídicos, em que poucas são as mulheres bacharéis em Direto que têm espaço no mercado editorial para publicarem obras. $\mathrm{O}$ espaço dado às mulheres como produtoras de conhecimento acadêmico é, geralmente, o que envolve questões ligadas à Lei Maria da Penha ou ao Estatuto da Criança e do

\footnotetext{
${ }^{7}$ Disponível em: < http://www.fgv.br/cpdoc/acervo/dicionarios/verbete-biografico/helio-pereira-bicudo>. Acesso em: 23 abr. 2021.

${ }^{8}$ Disponível em: <http://www.fgv.br/cpdoc/acervo/dicionarios/verbete-biografico/reale-junior-miguel>. Acesso em: 23 abr. 2021.

${ }^{9}$ Disponível em: <http://lattes.cnpq.br/6834563203257592>. Acesso em: 23 abr. 2021.
} 
Adolescente ou, ainda, a questões de gênero. Os especialistas em Direito do Trabalho, Direito Civil, Direito Tributário e outras áreas do campo de atividade jurídica são, em sua maioria, homens. O pouco espaço das publicações femininas no mercado editorial é apenas um dos aspectos da relação patriarcal vivida por mulheres com formação jurídica. $O$ fato de haver uma mulher entre os redatores do libelo e ela optar por fundamentar os seus argumentos com doutrinadores homens é um reflexo de que mesmo mulheres:

[...] aplicam a toda realidade, e, particularmente, às relações de poder em que se veem envolvidas, esquemas de pensamento que são produto da incorporação dessas relações de poder e que se expressam nas oposições fundadoras da ordem simbólica. (BOURDIEU, 2014, p. 54).

Além disso, como afirma Saffioti:

A maioria esmagadora das pesquisas lida com dados coletados junto a homens. Procuram-se homens para informar sobre aquilo que o cientista deseja saber sobre a realidade social. Raramente, os cientistas procuram ouvir mulheres. Este fato tem, no mínimo, duas conseqüências (sic) negativas. Uma delas é negativa para a própria ciência que, trabalhando apenas com informantes masculinos, deixa de lado informações preciosas passíveis de serem fornecidas por mulheres a partir de suas vivências. [...] A outra conseqüência (sic) diz respeito ao não-registro (sic) da atuação das mulheres no fazer história. (1987, p. 33, itálico no original).

Ao optarem por utilizar doutrinadores homens, os denunciantes demonstram que a relação patriarcal não está adstrita à relação privada, ela é uma relação hierárquica que se faz presente em todos os espaços sociais (Saffioti, 2011). Outro aspecto que precisa ser observado, ainda em relação aos doutrinadores que serviram de aporte teórico para o libelo acusatório, diz respeito à escolha lexical para se fazer referência a eles:

Figura 6: Trecho do Libelo Acusatório.

Em mais de uma oportunidade, a acusação asseverou que o
despacho inicial do Presidente da Câmara não poderia limitar o âmbito de análise dos
Senadores da República, que são os juizes da causa. Tal convicção não resulta de
casuísmo, mas da análise séria da melhor doutrina.

Fonte: <https://www12.senado.leg.br/noticias/materias/2016/08/22/veja-os-principais-documentos-do-processode-impeachment-de-dilma-rousseff > . Acesso em: 23 abr. 2021.

Figura 7: Trecho do Libelo Acusatório.

No sentido de que o processo para afastamento do Presidente da

República, muito embora seja circundado de garantias, não se confunde com um processo penal são também os ensinamentos de outros consagrados juristas pátrios. Vejamos.

Fonte: <https://www12.senado.leg.br/noticias/materias/2016/08/22/veja-os-principais-documentos-do-processode-impeachment-de-dilma-rousseff>. Acesso em: 23 abr. 2021. 
A doutrina apresentada pelos denunciantes é caracterizada, como observamos na figura 6 , pelo adjetivo melhor. Mas surge a pergunta: de acordo com quem ela é considerada a melhor doutrina? Não é nosso objetivo avançar na discussão sobre possíveis respostas a essa pergunta, mas evidenciar a escolha lexical feita pelos denunciantes. Na figura 7, os denunciantes optaram pelo adjetivo consagrados para compor seu enunciado. A palavra consagrado traz, em sua etimologia, o aspecto da sacralidade, da religiosidade. Percebemos, nessas escolhas lexicais, o valor axiológico que os denunciantes conferem ao que é dito pelos doutrinadores. A escolha de utilizar doutrinadores homens, portanto, além de refletir um posicionamento axiológico dos denunciantes, reflete uma condição patriarcal de produção do conhecimento acadêmico.

Sem uma visão ampla do patriarcado, podemos, de forma equivocada, caminhar para a conclusão de que ele se manifesta de forma prejudicial apenas às mulheres. Saffioti (2011), entretanto, afirma que os prejudicados pelo patriarcalismo são homens, mulheres e suas relações. Segundo a autora, o maior saldo negativo dessa relação patriarcal fica a cargo das mulheres, mas os homens também são afetados por essa relação de dominação, como podemos observar nas imagens a seguir:

Figura 8: Trecho do Libelo Acusatório.

Ao receber a denúncia, o então Presidente da Câmara restringiu

seus termos, excluindo os crimes relacionados à Petrobras, bem como aqueles anteriores

a 2015.

Nota-se que, muito embora o então Presidente da Câmara tenha

iniciado o processo para afastamento da denunciada, inegavelmente, auxiliou-a, ao despachar reduzindo a denúncia, conferindo à defesa argumento para furtar-se a enfrentar relevantes imputações.

Fonte: <https://www12.senado.leg.br/noticias/materias/2016/08/22/veja-os-principais-documentos-do-processode-impeachment-de-dilma-rousseff $>$. Acesso em: 23 abr. 2021.

Figura 9: Trecho do Libelo Acusatório.

Dentre as imputações extirpadas, destacam-se as referentes às

fraudes em torno das contas públicas, perpetradas aos bilhões, justamente em ano eleitoral, com o fim de iludir a população.

Fonte: <https://www12.senado.leg.br/noticias/materias/2016/08/22/veja-os-principais-documentos-do-processode-impeachment-de-dilma-rousseff $>$. Acesso em: 23 abr. 2021. 
Figura 10: Trecho do Libelo Acusatório.

A esse respeito, deve-se recordar que, não tivesse a acusação
referente ao Petrolão sido alijada do processo, poder-se-ia mostrar que o saque à
Petrobrás, antigo orgulho nacional, também se vincula aos crimes de que ora se trata.
Uma das evidências é o fato de o BNDES, por meio do PSI, Programa em que
ocorreram as mais elevadas pedaladas, ter injetado dinheiro público na Petrobrás, para
que pudesse, continuamente, ser sangrada pelos algozes do povo brasileiro. Vale
lembrar que muitos dos agentes presos e até condenados, no âmbito da Operação
Lavajato, são intimamente ligados ao Partido dos Trabalhadores, sigla da Presidente da
República.

Fonte: <https://www12.senado.leg.br/noticias/materias/2016/08/22/veja-os-principais-documentos-do-processode-impeachment-de-dilma-rousseff $>$. Acesso em: 23 abr. 2021.

Como podemos observar, os denunciantes alegaram que o Presidente da Câmara dos Deputados, embora tenha acatado a denúncia contra a ex-presidente Dilma e dado início ao pedido de afastamento desta, auxiliou-a ao restringir os termos da denúncia, por ter excluído os crimes relacionados à Petrobrás e os que eram anteriores a 2015 (período referente ao primeiro mandato de Dilma Rousseff como presidente). Os denunciantes utilizaram expressões como inegavelmente auxiliou-a, que as denúncias foram extirpadas, que fraudes foram perpetradas aos bilhões, alijadas, antigo orgulho nacional, ser sangrada pelos algozes do povo brasileiro. Essas expressões demonstram uma atitude axiológica de reprovação diante do posicionamento do Presidente da Câmara. Mais que isso, o fato de o Presidente da Câmara ter restringido a denúncia aos crimes relacionados ao então mandato vigente de Dilma Rousseff, segundo os denunciantes, proporcionou argumentos à defesa da ex-presidente, para que esta não fosse confrontada pelas imputações que lhes eram feitas. As quatro páginas que se seguem aos trechos destacados nas figuras acima referem-se à evocação aos doutrinadores tentando deslegitimar ação do Presidente da Câmara dos Deputados pelo argumento de autoridade de outros homens, corroborando a afirmação de Saffioti (2011) de que os homens também são afetados pelo patriarcado.

Em relação ao tratamento dado à ex-presidente Dilma, no libelo acusatório, percebemos que se reveste de formalidade. Ao falar dos crimes imputados a ela, entretanto, os denunciantes utilizam expressões adjetivas que refletem não só seus posicionamentos valorativos, mas que podem gerar comoção/revolta nos destinatários do enunciado. Observamos a utilização das expressões: maior escândalo de corrupção do mundo; pessoas muito próximas à senhora Presidente; inegavelmente, auxiliou-a; restou limpidamente evidenciado; criando nos eleitores a falsa sensação; Programas alardeados nos palanques; tiveram o fim de maquiar as contas públicas; as operações constituiram fraude e foram perpetradas para enganar a população; vontade deliberada do Governo Central de esconder fatos.

É importante, nesse ponto, compreendermos que as condutas imputadas à ex-presidente Dilma Rousseff, as chamadas pedaladas fiscais, também ocorreram, segundo a Advocacia Geral da União, nos mandatos anteriores dos ex-presidentes Fernando Henrique Cardoso e Luís Inácio Lula da Silva. A ex-presidente Dilma, entretanto, foi a única a ter as contas de governo rejeitadas 
pelo Tribunal de Contas da União ${ }^{10}$ e a sofrer um processo de impeachment. O fato de os expresidentes anteriores (que praticaram as mesmas condutas de Dilma Rousseff, mas que não tiveram sua confiabilidade política minada ao longo de seus mandatos pelo simples fato de serem homens) não terem suas contas de governo rejeitadas pelo Tribunal de Contas da União explicase pela relação patriarcal que rege a sociedade, mas em uma dimensão que exige o conhecimento do que Pateman (1993) chama de contrato sexual:

Tem-se, facilmente, a impressão de que os contratos sexual e social são dois contratos distintos, embora relacionados, e que o contrato sexual diz respeito à esfera privada. [...] O domínio público não pode ser totalmente compreendido sem a esfera privada, e do mesmo modo, o sentido do contrato original é desvirtuado sem as duas metades interdependentes da história. (PATEMAN, 1993, p. 18-19, grifo nosso).

O contrato social, segundo a autora, pressupõe o contrato sexual e a liberdade civil pressupõe o direito patriarcal. As teorias clássicas e tradicionais que tratam do contrato social não abordam sua outra metade, deixam de lado o contrato sexual. Entender o contrato sexual é entender a gênese do direito político e como o exercício desse direito é legitimado. Segundo Pateman, a liberdade civil "[...] depende do direito patriarcal" (1993, p. 19). A autora afirma que a diferença entre homens e mulheres é política. O contrato sexual, portanto, seria o meio "pelo qual os homens transformam o seu direito natural sobre as mulheres na segurança do direito patriarcal civil" (PATEMAN, 1993, p. 21). A autora prossegue afirmando que a legislação e o Estado não são duas formas de poder distintas, mas diferentes dimensões da estrutura complexa do patriarcado. Para ela, a participação da mulher na vida política não se resolve excluindo terminologicamente as referências ao sexo masculino ou ao sexo feminino, de modo a fazer, por exemplo, o uso do termo indivíduo em vez de homem ou mulher. A ideia de indivíduo, segundo Pateman (1993), parte do pressuposto de que esse termo abrange a todos, sendo uma categoria universalizante. A autora afirma, entretanto, que essa universalização é uma ficção política:

\begin{abstract}
Somente os homens - que criam a vida política - podem fazer parte do pacto original, embora a ficção política fale também às mulheres por meio da linguagem do "indivíduo". Uma mensagem curiosa é enviada às mulheres, que representam tudo o que o indivíduo não é, mas a mensagem deve ser continuamente transmitida porque o significado do indivíduo e do contrato social depende das mulheres e do contrato sexual. As mulheres têm que reconhecer a ficção política e falar sua língua, mesmo quando os termos do pacto original as exclui das conversações fraternais. (PATEMAN, 1993, p. 341, aspas no original).
\end{abstract}

Percebemos, portanto, que os seres políticos são, originariamente, os homens. Não é possível para as mulheres se fazerem presentes nessa ficção política, já que elas não são consideradas partes no contrato social; elas são, segundo Pateman (1993), o objeto desse contrato. Analisar uma única peça processual do impeachment da ex-presidente Dilma Rousseff retrata apenas algumas nuances do patriarcado que se manifestaram desde suas eleições e em seus mandatos como um todo. Foram vários os comentários em redes sociais que questionaram sua competência, insultando-a sexualmente de várias formas e questionando sua inteligência, desde sua nomeação como Ministra de Minas e Energia no governo Lula. É nesse ponto que percebemos o saldo negativo do patriarcado, em relação às mulheres, e como ele ainda é um fator estruturante da sociedade contemporânea: homens, que praticaram condutas semelhantes, não enfrentaram/enfrentam as situações de exposição pública, de críticas e de ataques à honra como as que observamos com a ex-presidente Dilma Rousseff. O libelo acusatório, analisado nesse trabalho, foi apenas uma manifestação patriarcal que tentou (revestindo-se do estilo, conteúdo

\footnotetext{
${ }^{10}$ Informação disponível em:< https://www12.senado.leg.br/noticias/materias/2016/10/05/tcu-entrega-aosenado-parecer-pela-rejeicao-das-contas-do-governo-de-2015>. Acesso em: 23 abr. 2021.
} 
semântico-objetal e construção composicional próprios desse gênero discursivo) legitimar a exclusão de uma mulher dos espaços públicos e dos cargos de chefia.

\section{CONSIDERAÇÕES FINAIS}

Conforme as lições de Saffioti $(1987 ; 2011)$ e de Pateman (1993), percebemos que o patriarcado é uma forma estruturante de nossa sociedade e se manifesta não apenas nas relações privadas, mas, também, e com grande expressividade, nos espaços públicos. Essas relações de dominação, segundo Saffioti (2011), não afetam somente as mulheres, afetam também os homens e suas relações. $\mathrm{Na}$ pesquisa sobre estatísticas de gênero (IBGE, 2021), observamos que o número de mulheres que participam da vida pública, que ocupam cargos de gestão ou que integram as forças armadas é menor que o de homens. Em 2017, 11,3 \% dos cargos eletivos no Brasil eram ocupados por mulheres. $E$ isso se levarmos em consideração apenas os itens da pesquisa que envolvem a participação das mulheres na vida pública. Há outros itens, como educação, estruturas econômicas, participação em atividades produtivas e acesso a recursos, que demonstram ainda mais a diferença entre homens e mulheres no que diz respeito a oportunidades de acesso e exercício dos direitos de forma igualitária. Como dissemos anteriormente, não era nosso objetivo adentrar nas discussões de gênero, entretanto, se abordarmos o patriarcado sob uma ótica não dicotômica de gênero, perceberemos que ele é ainda mais excludente.

Há, portanto, um senso comum na sociedade que tenta legitimar a exclusão das mulheres dos espaços públicos. Percebemos diversos discursos machistas que reforçam a ideia de maternidade e domesticidade da mulher, como, por exemplo, em anúncios publicitários dos mais variados itens de consumo, nas músicas, nas produções audiovisuais divulgadas em canais abertos e pagos, na literatura, enfim, na industrial cultural como um todo. Diante disso, o objetivo desse trabalho foi analisar o libelo acusatório do processo de impeachment da ex-presidente Dilma Rousseff levando em consideração as manifestações patriarcais que o cercam. Levamos em consideração as contribuições teóricas de Bakhtin e do Círculo, além de seus estudiosos contemporâneos e percebemos que o libelo acusatório do processo de impeachment se valeu de uma forma jurídica estilisticamente aceita, da construção composicional e do conteúdo temático próprios da acusação processual, para legitimar o discurso patriarcal de exclusão da mulher dos espaços públicos e dos cargos de poder.

Ao concluirmos momentaneamente nossas análises, ressaltamos que há ainda diversas perspectivas que podem ser analisadas dentro do processo de impeachment da ex-presidente Dilma Rousseff. Trazer as contribuições dos estudos de Bakhtin e do Círculo foi apenas uma perspectiva teórico-metodológica para analisar não apenas o gênero discursivo em si, mas as relações sociais por ele mediadas.

\section{REFERÊNCIAS}

AMORIM, Marília. O pesquisador e seu outro: Bakhtin nas Ciências Humanas. São Paulo: Musa. 2004.

BAKHTIN, Mikhail. Os gêneros do discurso. Tradução, organização, posfácio e notas de Paulo Bezerra. São Paulo: Editora 34, 2016.

BAKHTIN, Mikhail. Para uma filosofia do Ato Responsável. Tradução de Valdemir Miotello e Carlos Alberto Faraco. 3. ed. São Carlos: Pedro \& João Editores, 2017.

BICUDO, Hélio Pereira; REALE JÚNIOR, Miguel; PASCHOAL, Janaína Conceição. Libelo Acusatório. Disponível em: https://www12.senado.leg.br/noticias/materias/2016/08/22/veja- 
os-principais-documentos-do-processo-de-impeachment-de-dilma-rousseff. Acesso em: 07 jul. 2020.

BOURDIEU, Pierre. A dominação masculina. Tradução de Maria Helena Kühner. Rio de Janeiro: BestBolso, 2014.

BRAIT, Beth. Estilo. In: BRAIT, Beth (org). Bakhtin: conceitos-chave. São Paulo: Contexto, 2005. p. 79-102.

BULOS, Uadi Lammêgo. Curso de Direito Constitucional. 6a ed. São Paulo: Saraiva, 2011.

FARACO, Carlos Alberto; TEZZA, Cristóvão; CASTRO, Gilberto de. Apresentação. In: FARACO, Carlos Alberto; TEZZA, Cristóvão; CASTRO, Gilberto de (orgs). Vinte ensaios sobre Mikhail Bakhtin. Petrópolis: Vozes, 2006.

FARACO, Carlos Alberto. O problema do conteúdo, do material e da forma na arte verbal. In: BRAIT, Beth (org). Bakhtin, dialogismo e polifonia. São Paulo: Contexto, 2009. p. 95-111.

INSTITUTO BRASILEIRO DE GEOGRAFIA E ESTATÍSTICA. Estatísticas de gênero: indicadores sociais das mulheres no Brasil. 2.ed. n.38. 2021. Disponível em:

https://biblioteca.ibge.gov.br/visualizacao/livros/liv101551_informativo.pdf. Acesso em: 10 maio 2021.

KRESS, Gunther; VAN LEEUWEN, Theo. Reading Images: the gramar of visual desing. London: Routledge, 1996.

MARCHEZAN, Renata Coelho. Diálogo. In: BRAIT, Beth (org.). Bakhtin: outros conceitoschave. São Paulo: Contexto, 2006. p. 115-131.

PATEMAN, Carole. O contrato sexual. Tradução de Marta Avancini. Rio de Janeiro: Paz e Terra, 1993.

SAFFIOTI, Heleieth Iara Bongiovani. O poder do macho. São Paulo: Moderna, 1987.

SAFFIOTI, Heleieth Iara Bongiovani. Gênero, patriarcado, violência. São Paulo: Expressão Popular, 2011.

VOLÓCHINOV, Valentin. Marxismo e filosofia da linguagem: problemas fundamentais do método sociológico na ciência da linguagem. Tradução, notas e glossário de Sheila Camargo Grillo e Ekaterina Vólkova Américo. 2. ed. São Paulo: Editora 34, 2018. 